\title{
Optimal Control of Induction Motor for Photovoltaic Water Pumping System
}

\author{
Mustapha Errouha $^{1} \cdot$ Aziz Derouich ${ }^{1} \cdot$ Saad Motahhir ${ }^{2} \cdot$ Othmane Zamzoum $^{1}$
}

Received: 13 June 2019 / Accepted: 26 January 2020 / Published online: 19 February 2020

(C) Springer Nature Singapore Pte Ltd. 2020

\begin{abstract}
This paper aims to improve the induction motor (IM) performance for photovoltaic (PV) water pumping systems (PVWPS) without battery storage. The proposed technique is designed by direct torque control based on fuzzy logic controller (FLC). The purpose is to ensure optimal control of flux reference to reduce motor losses and hence, the efficiency of the PVWPS is improved. The maximum power point tracking (MPPT) is achieved using a variable step size Perturb and Observe (VSS P\&O) algorithm. The PV system incorporating the proposed technique is tested and compared with the control scheme based on constant flux reference under a real annual data of atmospheric conditions of the target site. The simulation results indicate the effectiveness of the proposed control strategy in terms of the reduction in stator current, optimizing flux, electrical speed and pumped water.
\end{abstract}

Keywords Optimal rotor flux · PV water pumping system · Loss minimization · Fuzzy logic controller · Efficiency optimization

\section{Introduction}

Nowadays, considerable effort has been devoted to finding a source of production of electrical energy without yielding $\mathrm{CO} 2$ emissions to the environment [1]. Solar photovoltaic $(\mathrm{PV})$ is one of the well-known sources of renewable energy which can be considered the best solution to produce clean electrical energy [2]. PV water pumping system is considered one of the most popular applications of PV power systems, particularly in remote area. Water pumping based on PV technology is a promising alternative to conventional pumping systems based diesel because there is no carbon emission or noise generation and it has a low maintenance cost.

Various types of electric motors are used in PV water pumping system, each has its pro and cons, among them, DC motor [3], permanent magnet synchronous (PMSM) [4, 5], brushless DC motor [6] and induction motor (IM) [7, 8]. Recently, the PV water pumping systems driven by IM are

Mustapha Errouha

mustapha.errouha@usmba.ac.ma

1 Laboratory of Production Engineering, Energy and Sustainable Development, Higher School of Technology, SMBA University, Fez, Morocco

2 Engineering, Systems and Applications Laboratory, ENSA, SMBA University, Fez, Morocco frequently used because these engines provide several advantages such as simple control thanks to the evolution of power electronics, low cost and free-maintenance $[9,10]$.

The most used control strategies for IM motor are Field Oriented Control (FOC) [11-14] and Direct Torque Control (DTC) [15-17]. Compared to FOC, DTC provides many advantages such as (i) simple implementation (ii) absence of current controllers, (iii) quick response control, (iv) less machine parameter dependence $[18,19]$. However, this control strategy has major inconvenient like (a) accurate estimation of torque and flux (a) high torque and flux ripples (d) variable switching frequency [20].

In the literature, several studies have been proposed to improve the performance of DTC. Some authors have used multilevel inverters to improve the DTC but this solution increases the cost due to number of power devices. Few researchers developed DTC by space vector modulation and discrete space vector modulation methods, however the accurate design of PI controllers is necessary [21]. DTC is also improved by employing Sliding Mode technique [19], this control strategy is robust and fast but it presents undesirable chattering [22]. A fixed switching frequency technique is also used to reduce the torque and flux ripples [23]. In the recent years, the use of artificial intelligent methods has attracted much attention from researchers. The artificial neural network is used to enhance the performance of the DTC but it needs a high-speed processor for implementation [20]. Fuzzy logic is also utilized 
which consists of replacing the hysteresis comparators and voltage vector selector by fuzzy logic controllers. This technique provides high performance by reducing the torque and flux ripples $[24,25]$.

The operation of the induction motors provides high efficiency under rated conditions (rated speed and torque). However, in many applications such as PVWPS, for most of the period during routine operations, IM operates far from the rated point which leads to reducing efficiency. In this context, the efficiency of the IM can be improved by minimizing the motor losses.

In most of the previous studies, the flux reference is maintained at a rated value in the whole speed range (from zero to rated value) $[16,26,27]$. However, the use of the nominal flux value can decrease the power factor and efficiency of the IM. Moreover, the operating with high flux values increases the iron losses in the magnetic circuit and leads the machine to saturation while, the lower flux level causes high joule losses. Therefore, a suitable control technique that maximizes the efficiency of the IM is highly desirable.

In this paper, a proposed approach associated with DTC based FLC which consists of determining the optimal flux level in order to improve the efficiency of PVWPS. The proposed technique uses the stator current as the objective function in the improvement process because it has been indicated that the stator current has more sensitivity to the flux variation. Consequently, an optimal control of direct axis (d- axis) stator current can result a reduction in flux level thus minimizing joules losses in IM. The optimal d-axis stator current is derived analytically using the loss equation of the IM and is employed in the dynamic model of the induction motor. The robustness of the proposed technique is approved by the reduction of the stator current, leading to a decrease in joule losses. As a result, the efficiency of the PVPWS is improved.

Because the analysis in seconds or minutes evaluates the performance of the system in a limited period, especially in PV water pumping system, it is essential to quantify the behavior of PV water pumping system in hours. The proposed PVWPS based optimal flux is evaluated and compared with the system that uses a constant reference flux under real climatic conditions for duration of one full year (8760 running hours) using Matlab/Simulink environment. It is found from the obtained results that proposed method improves the performance of the PVWPS while increasing the pumped water quantity, selecting the optimal flux level and reducing current amplitude. This paper is organized as follows: the PV system components are modeled in section II. The variable step size $(\mathrm{P} \& \mathrm{O})$ algorithm is presented in section III. The control strategy based on fuzzy logic controller is introduced in section IV. The proposed technique is described in section V. Section VI presents and analyses the simulation results. Finally, section VII concludes the paper giving some comments.

\section{Nomenclature}

a

Ia Output current of PV array[A].

$\mathrm{I}_{\mathrm{O}} \quad$ Diode saturation current [A].

$\mathrm{I}_{\mathrm{ph}} \quad$ Panel photocurrent [A].

I $\quad$ Rotor current [A].

$\mathrm{I}_{\mathrm{S}} \quad$ Stator current [A].

$\mathrm{K} \quad$ Boltzmann constant [J K -1$]$.

$\mathrm{K}_{\mathrm{p}} \quad$ Proportionality constant.

$L_{S} \quad$ Stator inductance $[\mathrm{H}]$.

$L_{r} \quad$ Rotor inductance [H].

$\mathrm{M} \quad$ Mutual inductance [H].

$\mathrm{N}_{\mathrm{s}} \quad$ Number of modules connected in series.

$\mathrm{N}_{\mathrm{p}} \quad$ Number of modules connected in parallel.

$\mathrm{p} \quad$ Pole pair number.

P, H, Q Characteristics of the pump for rotation speed[N].

$\mathrm{P}^{\prime}, \mathrm{H}^{\prime}, \quad$ Characteristics of the pump for rotation speed $[\mathrm{N}$ Q' '].

$\mathrm{q} \quad$ Electron charge [C].

$\mathrm{R}_{\mathrm{r}} \quad$ Rotor resistance $[\Omega]$.

$\mathrm{R} \quad$ Series resistance $[\Omega]$.

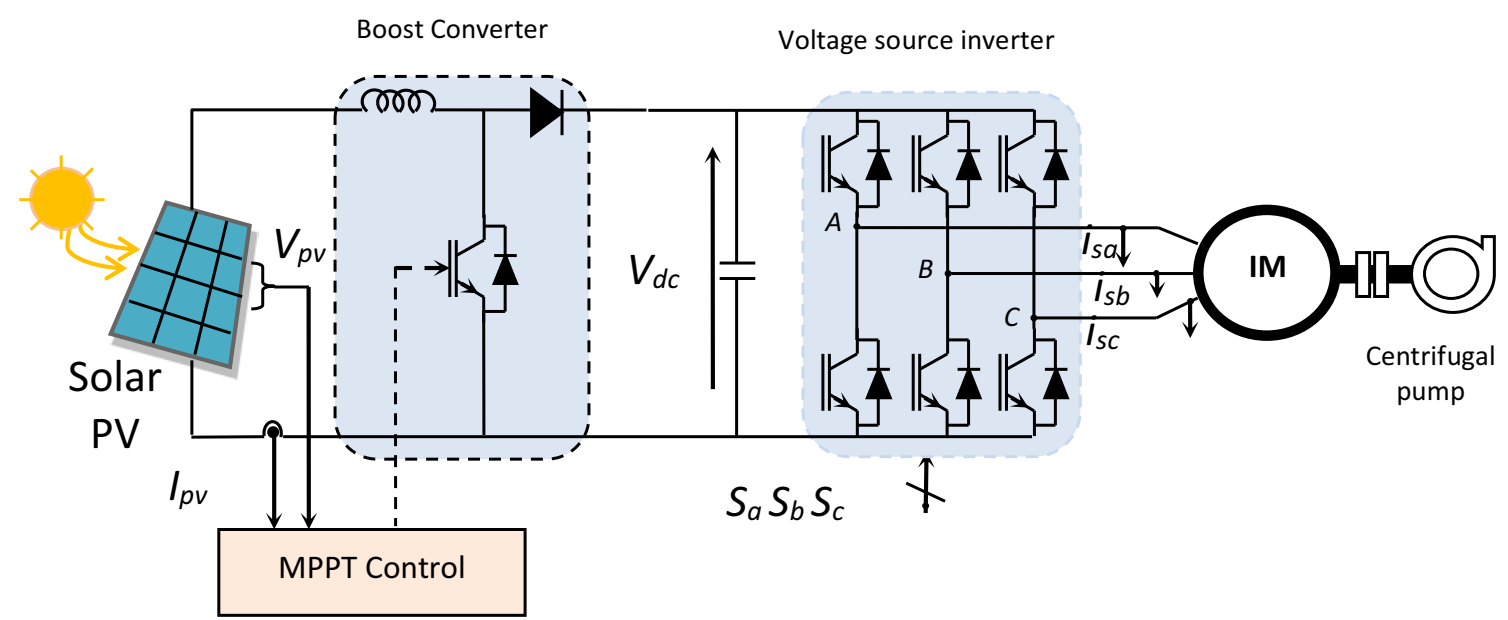

Fig. 1 Schematic diagram of the PVWPS 


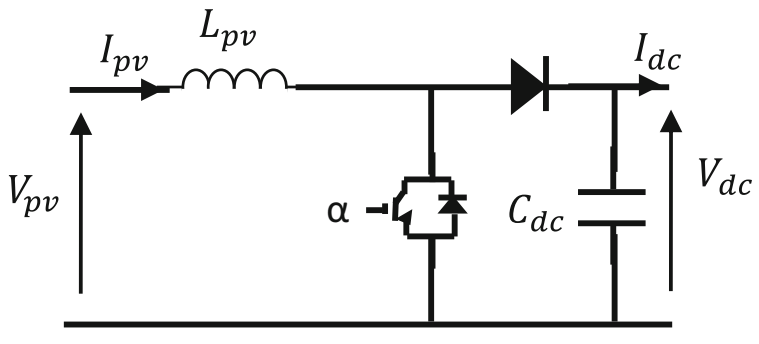

Fig. 2 DC-DC converter

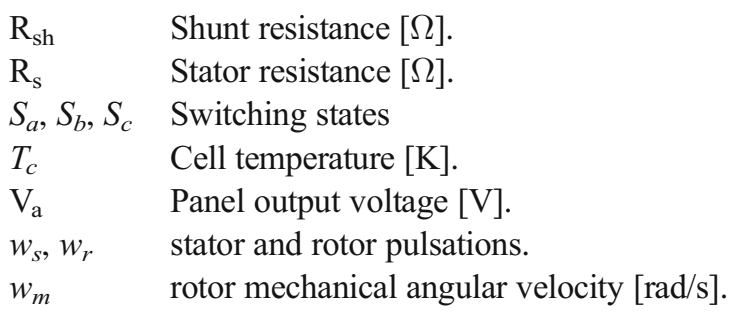

\section{Greek Letters}

$\alpha$ Duty cycle.

$\sigma \quad$ Dispersion coefficient.

$\theta_{s} \quad$ Position of stator flux.

$\Omega \quad$ Mechanical speed.

\section{Abbreviations}

DTC Direct Torque Control

FLC Fuzzy logic controller

IM Induction motor.

MPPT Maximum Power Point Tracking.
P \& O Perturb and observe.

PV Photovoltaic.

\section{Modeling of the Proposed PV Water Pumping System}

The proposed PV water pumping system (PVWPS) is illustrated in Fig. 1. It is composed of PV panel connected to boost converter which ensures operation at maximum power point by applying variable step size perturb and observe $(\mathrm{P} \& \mathrm{O})$ technique, voltage source inverter (VSI) and an induction motor connected to a centrifugal pump.

\section{PV Array}

In this work, a CSUN235_60P solar panel is adopted to achieve the necessary PV array. Hence, the output current of PV array can be expressed by [28]:

$$
I_{a}=N_{p} I_{p h}-N_{p} \mathrm{I}_{o}\left(\exp \left(\frac{1}{V_{t}}\left(\frac{V_{a}}{N_{s}}+\frac{R I_{a}}{N_{p}}\right)-1\right)-\frac{N_{p}}{R_{p}}\left(\frac{V_{a}}{N_{s}}+\frac{R I_{a}}{N_{p}}\right)\right.
$$

Where.

$$
V_{t}=\frac{a K T_{c}}{q} .
$$

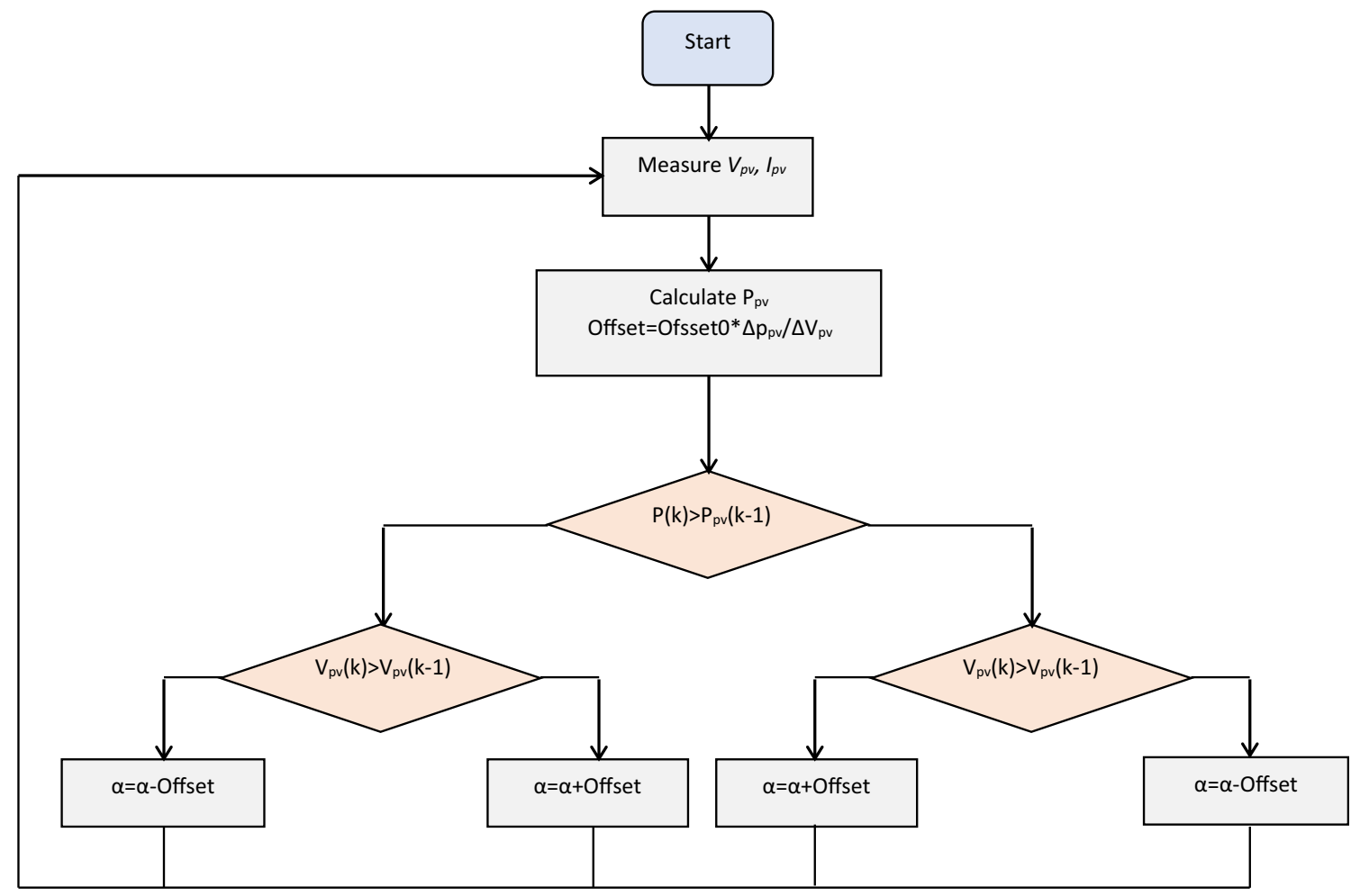

Fig. 3 Variable step size $\mathrm{P} \& \mathrm{O}$ 


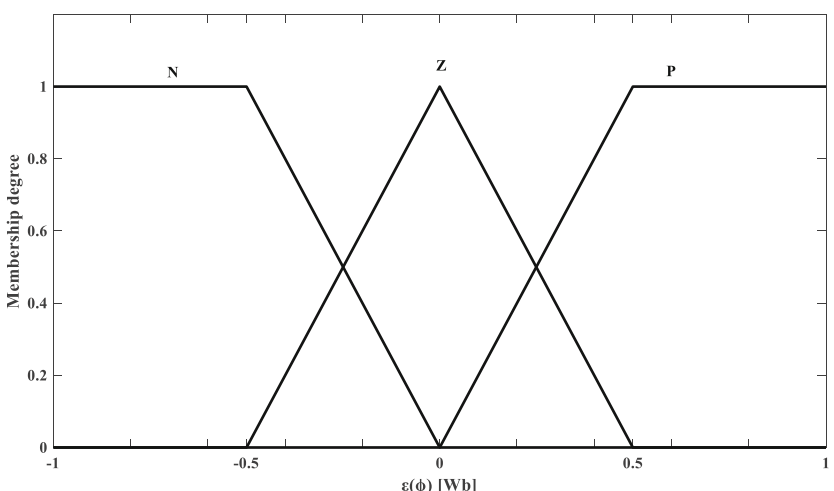

Fig. 4 The fuzzy membership functions of $\varepsilon_{\varphi}$

\section{DC-DC Converter}

Fig. 2 illustrates the boost converter which allows to converting DC voltage $\left(V_{p v}\right)$ to another DC voltage $\left(V_{d c}\right)$ and its main functioning is defined by the following equations [29]:

$V_{d c}=\frac{V_{p v}}{1-\alpha}$

$I_{d c}=I_{p v}(1-\alpha)$

\section{Inverter}

The inverter allows to control the induction motor and is represented by [30]:

$$
\begin{aligned}
& V_{a}=\frac{V_{d c}}{3}\left(2 S_{a}-S_{b-} S_{c}\right) \\
& V_{b}=\frac{V_{d c}}{3}\left(-S_{a}+2 S_{b-} S_{c}\right) \\
& V_{c}=\frac{V_{d c}}{3}\left(-S_{a}-S_{b}+2 S_{c}\right)
\end{aligned}
$$

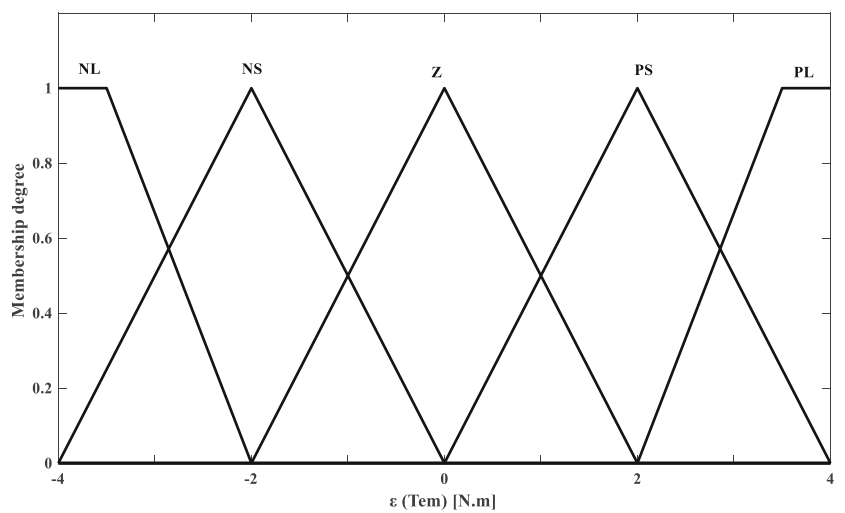

Fig. 5 The fuzzy membership functions of $\varepsilon_{\text {Tem }}$

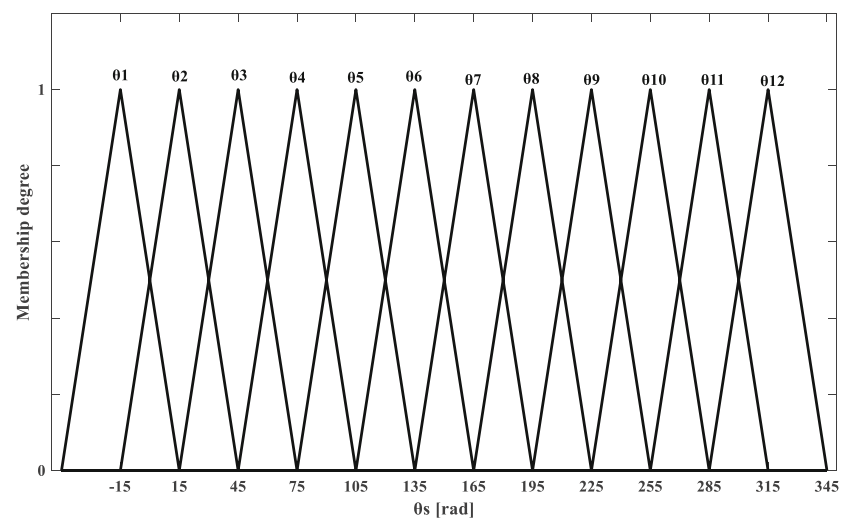

Fig. 6 The fuzzy membership functions of $\theta_{\mathrm{s}}$

\section{Induction Motor}

The application of the Concordia transformation to the three phases of the IM makes it possible to write the general model of the IM, which is resumed as follows [31]:

$$
\begin{aligned}
\frac{d I_{\alpha s}}{d t}= & -\left(\frac{R_{s}}{\sigma l_{s}}-\frac{R_{r}}{\sigma l_{r}}\right) I_{\alpha s}-w_{r} I_{\beta s}+\frac{R_{r}}{\sigma l_{r} l_{s}} \phi_{\alpha s}+\frac{w_{r}}{\sigma l_{s}} \phi_{\beta s} \\
& +\frac{1}{\sigma l_{s}} V_{\alpha s} \\
\frac{d I_{\beta s}}{d t}= & -\left(\frac{R_{s}}{\sigma l_{s}}-\frac{R_{r}}{\sigma l_{r}}\right) I_{\beta s}-w_{r} I_{\alpha s}+\frac{R_{r}}{\sigma l_{r} l_{s}} \phi_{\beta s}-\frac{w_{r}}{\sigma l_{s}} \phi_{\alpha s} \\
& +\frac{1}{\sigma l_{s}} V_{\beta s}
\end{aligned}
$$

\begin{tabular}{|c|c|c|c|c|c|c|c|c|c|c|c|c|c|}
\hline \multirow{2}{*}{\multicolumn{2}{|c|}{$\varepsilon \varphi \varepsilon_{\mathrm{T}}$}} & \multicolumn{12}{|l|}{$\theta_{\mathrm{s}}$} \\
\hline & Tem & $\theta 1$ & $\theta 2$ & $\theta 3$ & $\theta 4$ & $\theta 5$ & $\theta 6$ & $\theta 7$ & $\theta 8$ & $\theta 9$ & $\theta 10$ & & \\
\hline & PL & V2 & V3 & V3 & V4 & V4 & V5 & V5 & V6 & V6 & V1 & V1 & \\
\hline & PS & $\mathrm{V} 2$ & V2 & V3 & V3 & V4 & V4 & V5 & V5 & V6 & V6 & V1 & $\mathrm{V} 1$ \\
\hline & $\mathrm{Z}$ & V0 & V7 & V7 & V0 & V0 & V7 & V7 & V0 & V0 & V7 & V7 & \\
\hline & NS & V1 & V1 & V2 & $\mathrm{V} 2$ & V3 & V3 & V4 & V4 & V5 & V5 & & \\
\hline & NL & V6 & V1 & V1 & $\mathrm{V} 2$ & V2 & V3 & V3 & V4 & V4 & V5 & v & \\
\hline \multirow[t]{5}{*}{ Z } & PL & V2 & V3 & V3 & V4 & V4 & V5 & V5 & V6 & V6 & V1 & V1 & $\mathrm{V}^{2}$ \\
\hline & PS & V2 & V3 & V3 & V4 & V4 & V5 & V5 & V6 & V6 & V1 & V1 & $\mathrm{V}^{2}$ \\
\hline & $\mathrm{Z}$ & V7 & V0 & V0 & V7 & V7 & V0 & V0 & V7 & V7 & V0 & V0 & $\mathrm{V}^{\prime}$ \\
\hline & NS & V7 & V0 & V0 & V7 & V7 & V0 & V0 & V7 & V7 & V0 & V0 & $\mathrm{V}^{\prime}$ \\
\hline & NL & V6 & V1 & V1 & $\mathrm{V} 2$ & V2 & V3 & V3 & V4 & V4 & V5 & V5 & V \\
\hline \multirow[t]{5}{*}{$\mathrm{N}$} & PL & V3 & V4 & V4 & V5 & V5 & V6 & V6 & V1 & V1 & V2 & V2 & $\mathrm{V}_{3}^{3}$ \\
\hline & PS & V4 & V4 & V5 & V5 & V6 & V6 & $\mathrm{V} 1$ & V1 & V2 & V2 & V3 & $\mathrm{V}$ \\
\hline & $\mathrm{Z}$ & V7 & V7 & V0 & V0 & V7 & V7 & V0 & V0 & V7 & V7 & V0 & V \\
\hline & NS & V5 & V5 & V6 & V6 & V1 & V1 & V2 & V2 & V3 & V3 & V4 & \\
\hline & NL & V5 & V6 & V6 & $\mathrm{V} 1$ & V1 & V2 & $\mathrm{V} 2$ & V2 & V3 & V4 & V4 & \\
\hline
\end{tabular}

$\frac{d \phi_{\alpha s}}{d t}=V_{\alpha s}-R_{s} I_{\alpha s}$

Table 1 Fuzzy switching logic rule base 


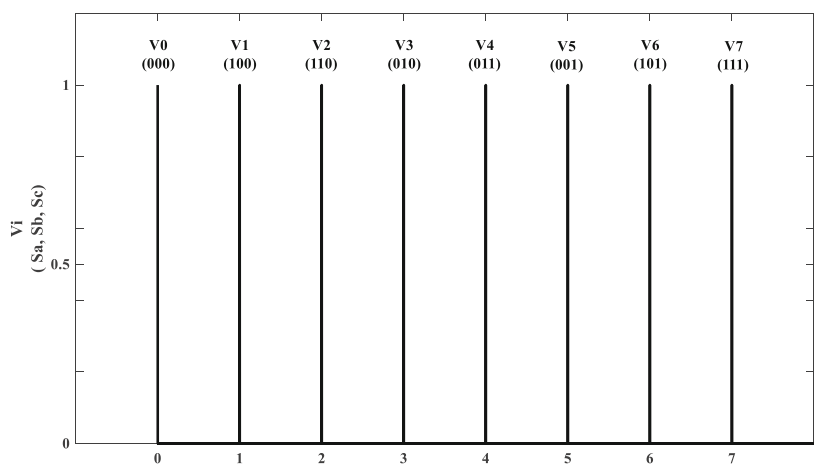

Fig. 7 The fuzzy membership functions of the output

$\frac{d \phi_{\beta s}}{d t}=V_{\beta s}-R_{r} I_{\beta s}$

The electromagnetic torque generated by the induction motor is given by:

$T_{e m}=\frac{3}{2} P\left(\phi_{\alpha s} I_{\beta s}-\phi_{\beta s} I_{\alpha s}\right)$

\section{Centrifugal Pump}

The load torque of the centrifugal pump is defined by:

$T_{p}=K_{p} \Omega^{2}$

According to Eqs. (14), the characteristics of the centrifugal pump can be determined for any rotation speed [32]:

$$
\begin{aligned}
\mathrm{Q}^{\prime} & =\mathrm{Q} \times\left(\frac{N^{\prime}}{N}\right) ; \mathrm{H}^{\prime}=\mathrm{H} \times\left(\frac{N^{\prime}}{N}\right)^{2} ; \mathrm{P}^{\prime} \\
& =\mathrm{P} \times\left(\frac{N^{\prime}}{N}\right)^{3}
\end{aligned}
$$

\section{Variable Step Size P\&O Algorithm}

Variable Step Size P\&O algorithm is used to track the MPP due to its advantages namely low oscillations and fast-tracking this, in turn, will improve the efficiency of PVWPS (Fig. 3) [33].
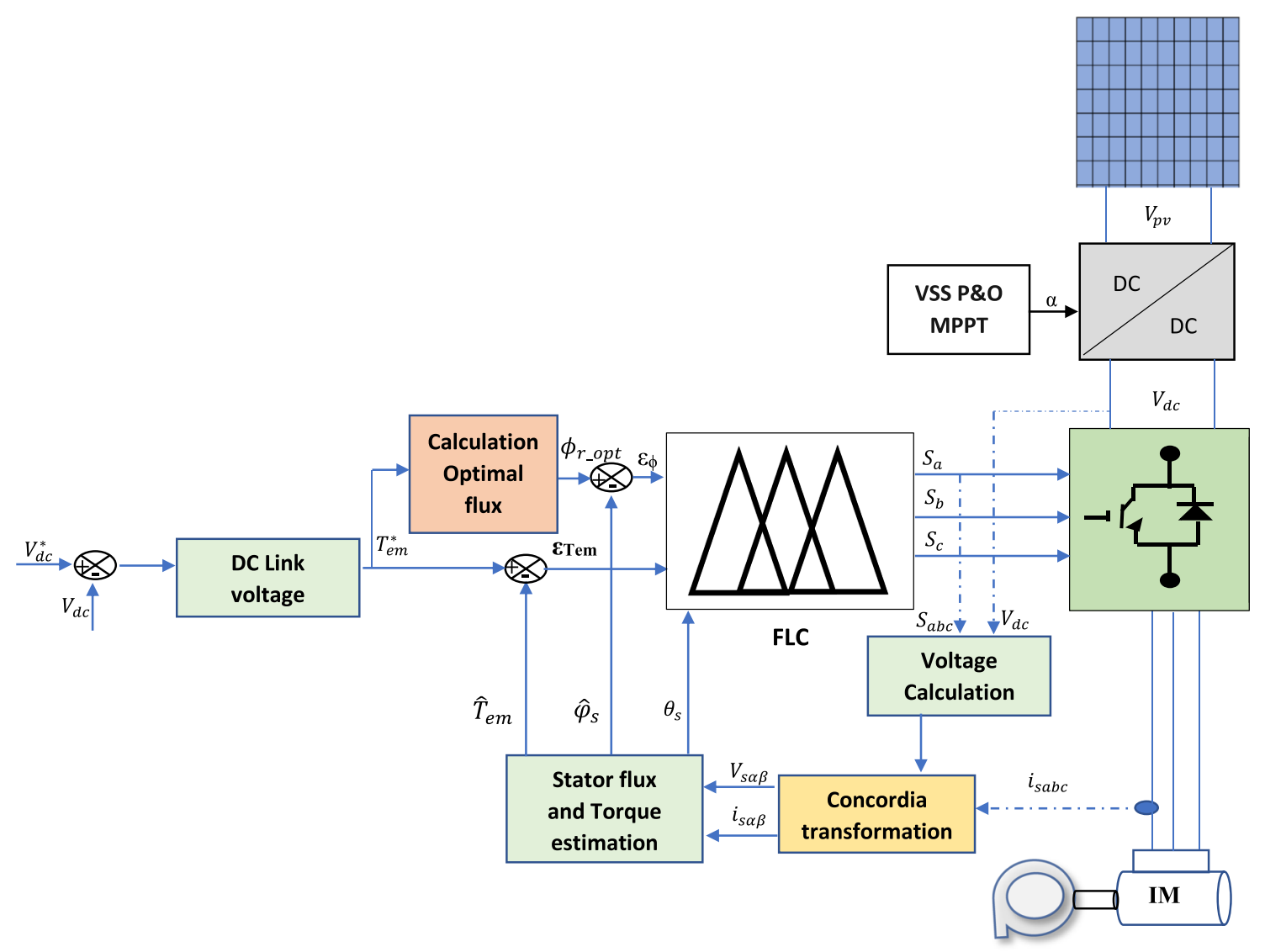

Fig. 8 Proposed PV water pumping system 


\section{DTC Based on Fuzzy Logic Controller}

With the aim of improving the performance of the system, a fuzzy logic controller is introduced to substitute the hysteresis controllers and switching table and select the suitable inverter vector state. The proposed FLC is composed of three inputs which are stator flux error $\varepsilon_{\varphi}$, torque error $\left(\varepsilon_{\mathrm{Tem}}\right)$ and sector angle $\left(\theta_{\mathrm{s}}\right)$ while, the outputs are presented by the converter switches $\left(S_{a}, S_{b}, S_{c}\right)$.

The FLC operation consists of 4 main steps:

\section{Fuzzification}

This step consists of converting the three input variables into fuzzy variables using membership functions (MF). Figure 4 shows an equidistant isosceles triangular and two symmetric trapezoidal MF which represent the stator flux error, while, Fig. 5 illustrates three equidistant isosceles triangular and two symmetric trapezoidal MF which represent the second input. The third input is the flux angle which its universe of discourse is divided into twelve fuzzy sets for more precision and represented by twelve equidistant isosceles triangular MF (Fig. 6).

\section{Fuzzy Control Rules}

The fuzzy rules are determined based on the expert knowledge to control the behavior of the FLC and stored in Table 1. This latter is composed of 180 control rules based on the compilation of conditional fuzzy statements stated as a set of IFTHEN rules.

\section{Fuzzy Inferences}

This step of the process utilizes Mamdani's procedure based on min-max decision. The weighting factor for $\mathrm{i}_{\mathrm{th}}$ rule $\left(\alpha_{i}\right)$ can be expressed by:

$\alpha_{i}=\min (\mu A i(e \varphi), \mu B i(e T), \mu C i(\theta))$
Fig. 9 Results of annual atmospheric conditions: (a) Irradiation profile (b) Cell temperature (c) PV power (d) Stator current (e) Flux components using FDTC (f) Flux components using FDTCO

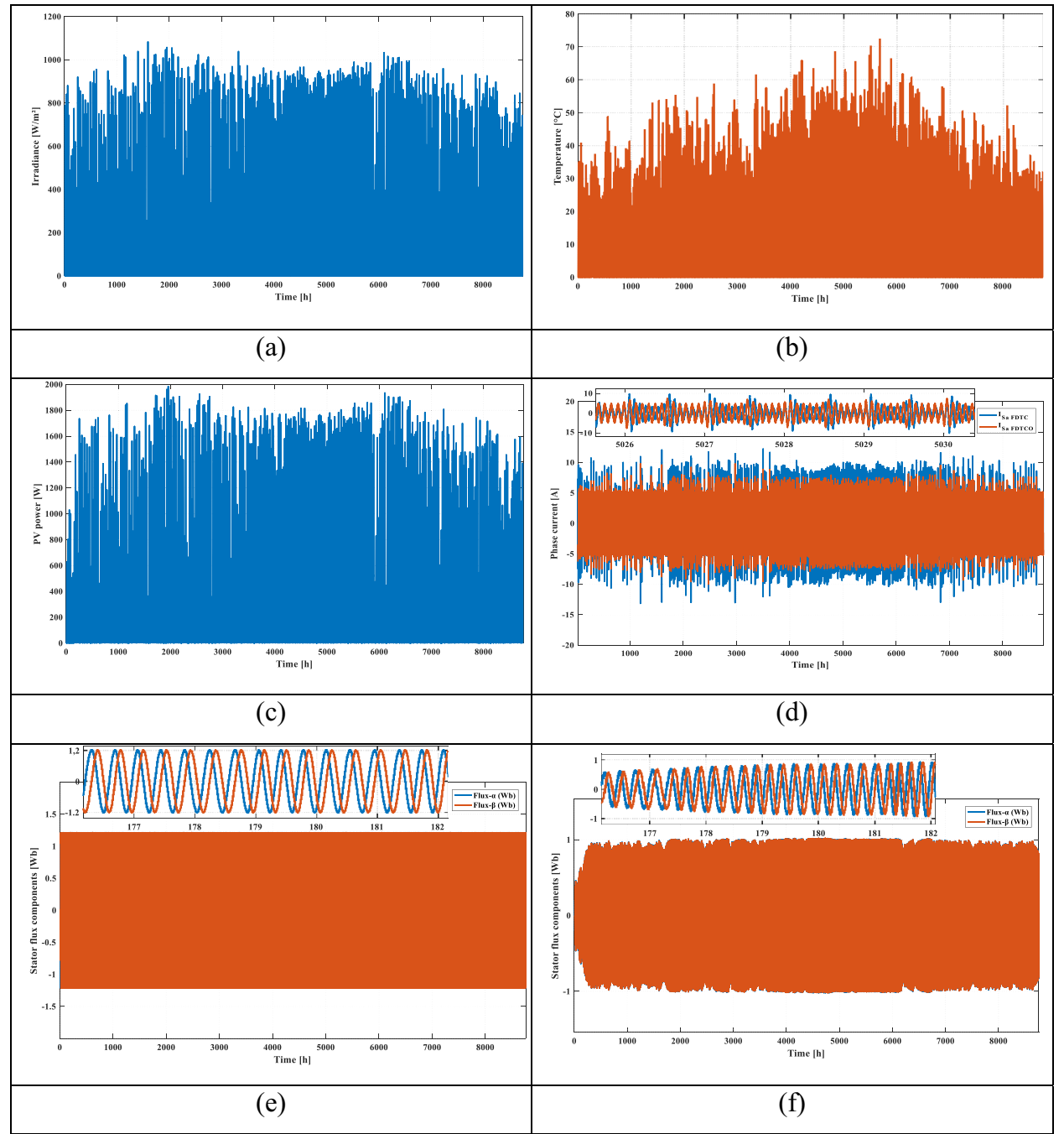


$\mu^{\prime} \operatorname{Vi}(V)=\max (\alpha i, \mu V i(V))$

Where:

$\mu A i(e \varphi),(e T), \mu C i(\theta)$ are the membership values of flux error, torque error and stator flux angle respectively.

\section{Defuzzification}

This step consists of using the Max method expressed by (17) to generate the crisp values varying from $\mathrm{V} 0$ to $\mathrm{V} 7$ to produce the control output (Fig. 7).

$\mu^{\prime} \operatorname{Vout}(V)=\max _{i=1}^{180} \max \left(\mu^{\prime} \operatorname{Vi}(V)\right)$
Fig. 10 Results of daily atmospheric conditions: (a) atmospheric conditions (b) PV power (c) Electric speed (d) water Flow (e) Flux components using FDTC (f) Flux components using FDTCO g) Stator current

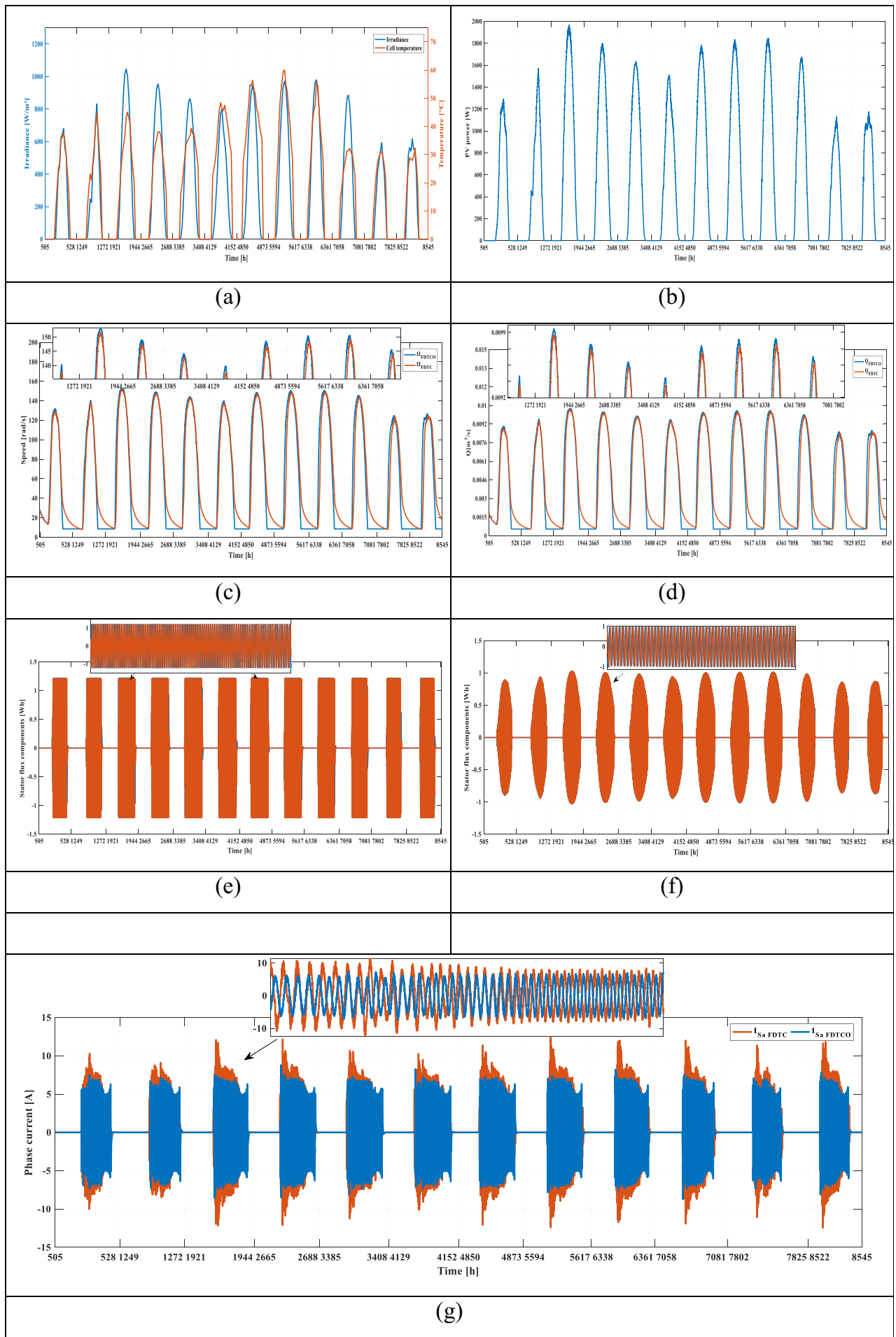


Stator flux and torque can be estimated by the following equations:

The components of stator flux are given by:

$\left\{\begin{array}{l}\widehat{\varphi}_{s \alpha}=\int_{0}^{t}\left(v_{s \alpha}-R_{s} \cdot i_{s \alpha}\right) \cdot d t \\ \widehat{\varphi}_{s \beta}=\int_{0}^{t}\left(v_{s \beta}-R_{s} \cdot i_{s \beta}\right) \cdot d t\end{array}\right.$

The electromagnetic torque is expressed by:

$\widehat{T}_{e m}=p \cdot\left(\widehat{\varphi}_{s \alpha} \cdot i_{s \beta}-\widehat{\varphi}_{s \beta} \cdot i_{s \alpha}\right)$

Where the amplitude and angle of the stator flux are calculated by:

$$
\left\{\begin{array}{l}
\widehat{\varphi}_{s}=\sqrt{\widehat{\varphi}_{s \alpha}^{2}+\widehat{\varphi}_{s \beta}^{2}} \\
\theta_{s}=\operatorname{arctg}\left(\frac{\widehat{\varphi}_{s \beta}}{\widehat{\varphi}_{s \alpha}}\right)
\end{array}\right.
$$

\section{Proposed Technique}

Based on the centrifugal pump theory, the quantity of the pumped water is increased with mechanical power at the pump shaft. Hence, the improvement of the pumped water is achieved by the maximization of the mechanical power as the insolation varies. The goal is obtained by the improvement of the motor efficiency which is expressed by (21) for every operating point.
$\eta=1-\frac{P_{\text {loss }}}{P_{\text {in }}}=1-\frac{P_{\text {loss }}}{V_{d s} i_{d s}+V_{q s} i_{q s}}$

Where:

$P_{\text {loss }}=P_{\text {in }}-P_{\text {out }}$ and $P_{\text {out }}=w_{m} T_{\text {em }}$.

Most of induction Motor control techniques use the rated value of flux as reference the command to ensure high dynamic performance. However, the high flux level produces additional core loss which leads to coming down efficiency. In that context, the proposed technique aims to determine the optimal reference flux which leads to increase the effectiveness of the PV water pumping system and reduces the motor losses. The proposed control strategy is based on the calculation of the copper losses (iron losses are neglected). The copper losses can be computed in $(\mathrm{d}, \mathrm{q})$ reference frame using direct stator current $i_{d s}$ and quadratic stator current $i_{q s}$ as follows:

The stator copper losses:

$P_{\text {cus }}=R_{s}\left(i_{d s}^{2}+i_{q s}^{2}\right)$

The rotor copper losses:

$P_{c u r}=R_{r}\left(i_{d r}^{2}+i_{q r}^{2}\right)$

Therefore, the total copper losses can be expressed by:

$P_{c u}=R_{s}\left(i_{d s}^{2}+i_{q s}^{2}\right)+R_{r}\left(i_{d r}^{2}+i_{q r}^{2}\right)$
Table 2 A comparative table between FDTC and the proposed method

\begin{tabular}{llllllll}
\hline & FDTC & \multicolumn{5}{l}{ FDTCO } \\
\cline { 2 - 3 } Months & $\begin{array}{l}\text { Flux } \\
(\mathrm{Wb})\end{array}$ & $\begin{array}{l}\text { Stator Current } \\
(\mathrm{A})\end{array}$ & $\begin{array}{l}\text { Water flow rate } \\
\left(\mathrm{m}^{3} / \mathrm{s}\right)\end{array}$ & & $\begin{array}{l}\text { Flux } \\
(\mathrm{Wb})\end{array}$ & $\begin{array}{l}\text { Stator Current } \\
(\mathrm{A})\end{array}$ & $\begin{array}{l}\text { Water flow rate } \\
\left(\mathrm{m}^{3} / \mathrm{s}\right)\end{array}$ \\
\hline Jan & 1.2 & 10 & 0.0081 & 0.88 & 7.4 & 0.0084 \\
Feb & 1.2 & 9.1 & 0.0087 & 0.92 & 7.1 & 0.009 \\
Mar & 1.2 & 11.97 & 0.0095 & 1.02 & 7.44 & 0.0097 \\
Apr & 1.2 & 12.18 & 0.0093 & 1 & 8.7 & 0.0095 \\
May & 1.2 & 10.68 & 0.0087 & 0.98 & 7.04 & 0.0092 \\
Jun & 1.2 & 10.28 & 0.0087 & 0.93 & 8.28 & 0.009 \\
Jul & 1.2 & 11.39 & 0.0092 & 1 & 7.23 & 0.0095 \\
Aug & 1.2 & 12.38 & 0.0092 & 1 & 7.33 & 0.0096 \\
Sep & 1.2 & 11.95 & 0.0094 & 1 & 8.02 & 0.0096 \\
Oct & 1.2 & 12.02 & 0.0091 & 0.98 & 7.22 & 0.0092 \\
Nov & 1.2 & 11.23 & 0.007 & 0.85 & 7.1 & 0.008 \\
Dec & 1.2 & 12.23 & 0.0071 & 0.86 & 7.8 & 0.008 \\
\hline
\end{tabular}


The rotor copper losses can be expressed considering $i_{d s}=0$ and $i_{q r}=-\left(\frac{M}{L_{r}}\right) i_{q s}$ in field-oriented d- q frame by:

$P_{c u r}=R_{r}\left(\frac{M}{L_{r}}\right) 2 i_{q s}^{2}$

Replacing Eq. (25) into (24), we obtain:

$P_{c u}=R_{s}\left(i_{d s}^{2}+i_{q s}^{2}\right)+R_{r}\left(\frac{M}{L_{r}}\right)^{2} i_{q s}^{2}$

Thus, the stator currents rotor in terms of flux and electromagnetic torque can be written as:

$i_{d s}=\frac{\phi_{r}}{M}$

$i_{q s}^{*}=C_{e m}^{*} \frac{L_{r}}{M p \phi_{r}^{*}}$

Replacing Eq. (27) and (28) into (26), the total losses expression can be written in terms of direct stator current $i_{d s}$ as follows:

$P_{c}=R_{s} i_{d s}^{2}+\left(\left(R_{r}\left(\frac{M}{L_{r}}\right)^{2}+R_{s}\right)\left(C_{e m}^{*} \frac{L_{r}}{p M^{2} i_{d s}}\right)^{2}\right.$

From Eq. (29), it's clear that the losses depend on the value of $i_{d s}$ which controlled the rotor flux $\phi_{r}^{*}$. This involves the motor losses that can be controlled when the internal parameters of the induction motor remain unchanged under the constant load torque. Hence, the derivative of Eq. (30) allows to providing the optimal reference flux which ensures the minimum losses without degrading the performance of IM.

$\frac{d P_{c}}{d i_{d s}}=0$

Therefore, the direct stator current $I_{d s o p t}$ in field-oriented $(d, q)$ system ensuring the optimal reference value of the rotor flux is given by:

$I_{d s o p t}=K_{o p t} i_{q s}^{*}$

Where

$K_{\text {opt }}=\sqrt{1+\left(\frac{M}{L_{r}}\right)^{2} \frac{R_{r}}{R_{s}}}$

\section{Simulation Results}

The performance of the PV water systems is influenced by the variation of the climatic conditions such as solar radiation and ambient temperature. For this reason, the proposed method (Fig. 8) is evaluated under real climatic data of Fez, Morocco. Because the analysis in seconds or minutes evaluates the performance of the system in a limited period, especially in PV water pumping system, it is essential to quantify the behavior of PV water pumping system in hours. The configuration for the proposed PV system consists of eight PV panels (Appendix Table 3) connected in series to provide the needed power to run the motor whose characteristics are listed in Appendix Table 4. The components of PV water pumping system are presented in Appendix Table 5. To obtain a fair comparison possible, the proposed control strategy (FDTCO) is compared to FDTC in the same conditions.

\section{Annual Analysis of PVWPS Performance}

In the first step, the proposed PV system based on optimal flux is evaluated for one complete year (8760 running hours) using MATLAB/Simulink software. A comparative study of the proposed control strategy with FDTC using the rated value of flux $(1.2 \mathrm{~Wb})$ as reference has been performed. Figure $9 \mathrm{a}$ and $\mathrm{b}$ show the annual variation of the solar radiation and cell temperature respectively. Figure 9c illustrates the extracted PV power from the PV panel. Figure 9d shows the stator current of both techniques, it can be seen that the proposed control scheme reduces the stator current amplitude compared to FDTC, which leads to minimizing the copper losses. Hence the efficiency of the PV system is improved. Figure $9 \mathrm{e}$ and f illustrate the responses of stator flux using FDTC and the proposed technique respectively. It is clearly seen that the stator flux is always kept constant using FDTC. Moreover, operating with high value of flux can lead to saturation of the IM. Contrary to proposed technique, the reference flux is variable which allow minimizing of the losses. In addition, it doesn't reach its rated value. Hence, the proposed method indicates its performance.

\section{Daily Analysis of PVWPS Performance}

For more accuracy, the PV system is tested for the twenty-first day of each month. Figure 10a indicates the profile of solar radiation and cell temperature. Figure $10 \mathrm{~b}$ illustrates the extracted PV power. Figure 10c and d show the responses of speed and water flow with zoom-in view of the twenty-first day of each month for both methods. Using the proposed technique based on loss minimization, the volume of water pumped is higher compared to FDTC. This is obtained due to increasing the mechanical power at the pump shaft under the constant load torque by reducing the motor losses. Figure 10e and fillustrate the developed flux. It can be observed that the flux is variable during all the 
operating of the process to select the optimal value which ensures the reduction of the losses using the proposed technique. Contrary to FDTC, the flux remains constant. Figure $10 \mathrm{~g}$ shows the absorbed stator current for both control strategies. We can notice that the proposed technique provides a remarkably reduction of current compared with FDTC which allows to reduce the copper losses and consequently, the efficiency of the PVWPS is improved. Thus, a high starting current degrades the performance of the IM. Moreover, the proposed method reduces the starting current which allows the increase the IM lifetime.

A comparative table regarding pumped water, stator current and flux amplitude with the main values obtained in simulation for the two control strategies is presented in Table 2. We can conclude that the proposed technique based on loss minimization provides better performance compared to FDTC.

\section{Conclusion}

This paper describes an optimal design of FLC based on DTC with loss minimization method for PV systems. The proposed control strategy aims to improve the performance of the PV water pumping by optimizing IM energy. The purpose is to select the optimal value of reference flux which allows to reduce the copper losses of IM and therefore the efficiency of the PV systems is improved. A comparison between the PVWPS with the proposed method and the system based on constant value of reference flux for one Typical Meteorological Year for the Moroccan city (Fez) is presented. To conclude, the proposed control strategy gives excellent performances, in particular the selection of the optimal flux, minimization of the stator current and losses of the IM and the increase of the efficiency of PVWPS.

\section{Appendix}

Table 3 Electrical characteristics of the csun235-60p photovoltaic model

Photovoltaic Panel CSUN235-60P

\begin{tabular}{ll}
\hline Maximum Power, Pmax & $235 \mathrm{~W}$ \\
\hline Open Circuit Voltage, Voc & $36.8 \mathrm{~V}$ \\
Short Circuit Current, Isc & $8.59 \mathrm{~A}$ \\
Maximum Power Voltage Pmax,Vmpp & $29.5 \mathrm{~V}$ \\
Maximum Power Current Pmax, Impp & $7.97 \mathrm{~A}$ \\
Standard Test Condition (STC) & $1000 \mathrm{~W} / \mathrm{m}^{2}, 25{ }^{\circ} \mathrm{C}, \mathrm{AM} 1.5$ \\
$\begin{array}{l}\text { Number of cell } \\
\text { Temperature coefficient of open-circuit } \\
\quad \text { voltage Voc, Kv }\end{array}$ & 60 \\
$\begin{array}{l}\text { Temperature coefficient of short-circuit } \\
\text { current Isc, Ki }\end{array}$ & $0.07 \% /{ }^{\circ} \mathrm{C}$ \\
\hline
\end{tabular}

Table 4 Parameters of induction machine

Pairs poles number 2

\begin{tabular}{llll}
\hline Stator resistance $[\Omega]$ & 4.85 & Mutual inductance $[\mathrm{H}]$ & 0.258 \\
\hline Rotor resistance $[\Omega]$ & 3.805 & Inertia moment $\left[\mathrm{Kg} . \mathrm{m}^{2}\right]$ & 0.031 \\
Stator inductance $[\mathrm{H}]$ & 0.274 & Nominal power $[\mathrm{KW}]$ & 1.5 \\
Rotor inductance $[\mathrm{H}]$ & 0.274 & Viscous Friction [N.m.s/rad] & 0.00114 \\
\hline
\end{tabular}

Table 5 Design of parameters of the system

\begin{tabular}{ll}
\hline Component & Value \\
\hline$V_{d c}^{*}$ & $400 \mathrm{~V}$ \\
$C_{d c} \quad \alpha$ & $2000 \mu \mathrm{F}$ \\
\multicolumn{1}{c}{$\alpha$} & 0.26 \\
$L_{p v}$ & $3 \mathrm{mH}$ \\
\hline
\end{tabular}

\section{References}

1. Allouhi A et al (2019) PV water pumping systems for domestic uses in remote areas: sizing process, simulation and economic evaluation. Renew Energy 132:798-812

2. Yadav K, Kumar A, Sastry OS, Wandhare R (2019) Solar photovoltaics pumps operating head selection for the optimum efficiency. Renew Energy 134:169-177

3. Poompavai T, Kowsalya M (2019) Control and energy management strategies applied for solar photovoltaic and wind energy fed water pumping system: A review. Renew Sust Energ Rev 107(November 2018):108-122

4. Antonello R, Carraro M, Costabeber A, Tinazzi F, Zigliotto M (2017) Energy-efficient autonomous solar water-pumping system for permanent-magnet synchronous motors. IEEE Trans Ind Electron 64(1):43-51

5. Singh B, Murshid S (2018) A grid-interactive permanent-magnet synchronous motor-driven solar water-pumping system. IEEE Trans Ind Appl 54(5):5549-5561

6. Kumar R, Singh B (2016) BLDC motor-driven solar PV Array-fed water pumping system employing zeta converter. IEEE Trans Ind Appl 52(3):2315-2322

7. Mudlapur A, Ramana VV, Damodaran RV, Balasubramanian V, Mishra S (2019) Effect of partial shading on PV fed induction motor water pumping systems. IEEE Trans Energy Convers 34(1):530-539

8. Mustapha Errouha, Aziz Derouich, Babak Nahid-Mobarakeh, Saad Motahhir, Abdelaziz El Ghzizal, (2019) Improvement control of photovoltaic based water pumping system without energy storage. Solar Energy 190:319-328

9. Talbi B, Krim F, Rekioua T, Mekhilef S, Laib A, Belaout A (2018) A high-performance control scheme for photovoltaic pumping system under sudden irradiance and load changes. Sol Energy 159(November 2017):353-368

10. Singh B, Sharma U, Kumar S (2018) Standalone photovoltaic water pumping system using induction motor drive with reduced sensors. IEEE Trans Ind Appl 54(4):3645-3655 
11. Wang F, Zhang Z, Mei X, Rodríguez J, Kennel R (2018) Advanced control strategies of induction machine: Field oriented control, direct torque control and model predictive control. Energies 11(1)

12. Wang K, Li Y, Ge Q, Shi L (2018) An improved indirect fieldoriented control scheme for linear induction motor traction drives. IEEE Trans Ind Electron 65(12):9928-9937

13. Talla J, Leu VQ, Smidl V, Peroutka Z (2018) Adaptive speed control of induction motor drive with inaccurate model. IEEE Trans Ind Electron 65(11):8532-8542

14. Errouha M, Derouich A (2019) Study and comparison results of the field oriented control for photovoltaic water pumping system applied on two cities in Morocco. Bull Electr Eng Informatics 8(4):1-7

15. Gdaim S, Mtibaa A, Mimouni MF (2014) Design and Experimental Implementation of DTC of Induction Machine based on Fuzzy Logic Control on FPGA. 6706, no. c

16. Sudheer H, Kodad SF, Sarvesh B (2017) Improvements in direct torque control of induction motor for wide range of speed operation using fuzzy logic. J. Electr Syst Inf Technol

17. Achour A, Rekioua D, Mohammedi A, Mokrani Z, Rekioua T, Bacha S (2016) Application of direct torque control to a photovoltaic pumping system with sliding-mode control optimization. Electr Power Components Syst 44(2)

18. Mesloub H, Benchouia MT, Boumaaraf R, Becherif M (2018) Design and implementation of DTC based on AFLC and PSO of a PMSM. Math Comput Simul

19. Benamor A, Benchouia MT, Srairi K, Benbouzid MEH (2019) A novel rooted tree optimization apply in the high order sliding mode control using super-twisting algorithm based on DTC scheme for DFIG. Int J Electr Power Energy Syst 108(November 2018):293-302

20. Zemmit A, Messalti S, Harrag A (2018) A new improved DTC of doubly fed induction machine using GA-based PI controller. Ain Shams Eng J 9(4):1877-1885

21. Mahanta U, Patnaik D (2015) Dynamic Modeling and Simulation of SVM-DTC of Five Phase Induction Motor. pp. 3-8

22. El Ouanjli N, Motahhir S, Derouich A, El Ghzizal A, Chebabhi A, Taoussi M (2019) Improved DTC strategy of doubly fed induction motor using fuzzy logic controller. Energy Rep 5(February):271279

23. Ismail H, Jidin A, Patkar F, Tarusan SA, Razi A, Rahim MK (2017) Constant switching frequency torque controller for DTC of induction motor drives with three-level NPC inverter. PECON 2016-2016 IEEE 6th Int. Conf. Power Energy, Conf. Proceeding, pp. $210-215$

24. Errouha M, Derouich A, Motahhir S, Zamzoum O, El Ouanjli N, El Ghzizal A (2019) Optimization and control of water pumping PV systems using fuzzy logic controller. Energy Rep 5:853-865

25. Ayrir W, Ourahou M, El Hassouni B, Haddi A (2018) Direct torque control improvement of a variable speed DFIG based on a fuzzy inference system. Math Comput Simul

26. Venugopal C (2010) Fuzzy logic based DTC for speed control of matrix converter fed induction motor. PECon2010-2010 IEEE Int. Conf. Power Energy, pp. 753-758

27. El Ouanjli N, Derouich A, El Ghzizal A, Chebabhi A, Taoussi M, Bossoufi B (2018) Direct torque control strategy based on fuzzy logic controller for a doubly fed induction motor. IOP Conf. Ser Earth Environ Sci 161(1)

28. Muhsen DH, Khatib T, Abdulabbas TE (2018) Sizing of a standalone photovoltaic water pumping system using hybrid multi-criteria decision making methods. Sol Energy 159(November 2017):1003-1015

29. Motahhir S, Chalh A, El Ghzizal A, Sebti S, Derouich A (2017) Modeling of photovoltaic panel by using proteus. J Eng Sci Technol Rev 10(2):8-13

30. Yahyaoui I (2016) Specifications of photovoltaic pumping systems sizing, fuzzy energy management specifications of photovoltaic pumping systems

31. Reza CMFS, Islam MD, Mekhilef S (2014) A review of reliable and energy efficient direct torque controlled induction motor drives. Renew Sust Energ Rev 37:919-932

32. Rawat R, Kaushik SC, Lamba R (2016) A review on modeling, design methodology and size optimization of photovoltaic based water pumping, standalone and grid connected system. Renew Sust Energ Rev 57:1506-1519

33. Motahhir S, El Hammoumi A, El Ghzizal A (2019) The Most Used MPPT Algorithms: Review and the Suitable Low-cost Embedded Board for Each Algorithm. J Clean Prod 118983(November)

Publisher's Note Springer Nature remains neutral with regard to jurisdictional claims in published maps and institutional affiliations. 